\title{
Compósitos Obtidos de Resíduos de Papel, Reforçados com Pó de Serragem e de Gesso
}

\section{Composites Obtained from Waste Paper and Reinforced Sawdust and Plaster}

\author{
Juliana da Silva Ribeiro ${ }^{1}$ e Juan Carlos Valdés Serra ${ }^{2}$ \\ ${ }^{1}$ Engenheira ambiental e-mail: juliana.s.ribeiro@outlook.com \\ 2 Professor Doutor da Universidade Federal do Tocantins
}

Recebido em julho/2014, aceito em agosto, publicado Novembro 2014

\begin{abstract}
Resumo: Foram investigadas propriedades físicas (densidade de massa aparente; absorção de água) e mecânicas (resistência à compressão e à tração na flexão; módulo de elasticidade) de materiais compósitos com matriz de papel usado reforçado com pó de serragem e de gesso. Os ensaios foram realizados conforme normas brasileira e europeia. No ensaio de densidade de massa no estado endurecido os modelos apresentaram baixa densidade significando que são materiais leves. Neste ensaio o compósito que melhor se aproximou dos resultados estabelecidos pela norma, quando se comparado a materiais de alvenaria, foi o modelo contendo $35 \%$ matriz de papel, $15 \%$ pó de serragem e $45 \%$ pó de gesso. A retenção de água e a resistência à tração na flexão foram aumentadas pela presença das fibras vegetais. Os resultados do coeficiente de capilaridade no ensaio de absorção de água variaram entre 0,010 a $0,019 \mathrm{~kg} / \mathrm{m}^{3} \cdot \mathrm{min}^{1 / 2}$. Neste ensaio os modelos que apresentaram menor absorção de água foram os com $35 \%$ de papel, $45 \%$ pó de serragem e $15 \%$ pó de gesso e contendo $75 \%$ de papel e $20 \%$ pó de serragem. O módulo de elasticidade poderia ser aumentado se fosse possível conhecer a espécie da madeira do pó de serragem utilizado, pois o tipo de madeira é de grande influência na elasticidade. No ensaio de compressão axial os valores foram de 2,5 a 8,5 MPa. Os resultados dos ensaios revelaram que a composição do material é viável, pois foram capazes de resistir à considerável quantidade de carga, sendo adequado para aplicações não estruturais de interiores.
\end{abstract}

Palavras-Chave: reciclagem de materiais; aplicações não estruturais; reutilização.

\begin{abstract}
And mechanical (compressive strength and tensile strength in bending, modulus of elasticity) of composite materials with paper used matrix reinforced with sawdust and plaster; physical properties (water absorption apparent mass density) were investigated. The tests were performed according to European standards and Brazilian. In the trial of mass density in the hardened state models showed low density meaning they are lightweight materials. In this test the composite that best approached the results derived by the standard when compared to masonry materials, was the model matrix containing $35 \%$ paper, $15 \%$ sawdust and $45 \%$ plaster dust. Water retention and tensile strength in bending were increased by the presence of vegetable fibers. The results of the assay coefficient of capillary water uptake ranged from 0.010 to $0.019 \mathrm{~kg} / \mathrm{m} 3 \mathrm{~min} 1 / 2$. In this test the specimens had lower water absorption were $35 \%$ paper, $45 \%$ sawdust and $15 \%$ powdered gypsum and paper containing $75 \%$ and $20 \%$ sawdust. The elastic modulus could be increased if it were possible to know the species of wood sawdust powder used as the type of wood is of great influence on the elasticity. In axial compression test values were 2.5 to $8.5 \mathrm{MPa}$. The test results revealed that the composition of the material is feasible, since they were able to withstand considerable amount of charge being suitable for interior non-structural applications. Keywords: recycling of materials; non-structural applications; reuse.
\end{abstract}

\section{Introdução}

Estudos sobre a reutilização de materiais são de grande interesse tanto do ponto de vista ambiental, uma vez que reduz o impacto ambiental de materiais descartados, como também do ponto de vista econômico, com a potencial redução de custos em tratamento ou eliminação dos resíduos. Além disso, os materiais que seriam descartados podem servir de matéria prima para fabricação de outros produtos.

O processo de reciclagem do papel tratase de um procedimento que permite recuperar as fibras celulósicas do papel velho e incorporá-las na fabricação de novo papel ou outro material compósito (Sena et al, 2011). É o resultado de uma série de atividades, pela qual os 
materiais que seriam descartados em coletados, separados e processados para serem usados como matéria-prima na fabricação de novos produtos.

Conforme Calegari et al (2004) fibras de papel recicláveis estão sendo utilizadas para confeccionar chapas de formas de concreto, segundo autor, essas chapas de fibras demonstraram boa resistência à flexão, colagem interna e resistência à água. Porém, as fibras recicladas perdem qualidades importantes devido à perda de ligações entre fibras, que por sua vez é causada durante $o$ processo de reciclagem onde uma grande porcentagem das fibras é quebrada (Cardoso et al, 2012), com isso é importante agregar ao papel materiais que o deixem mais resistente.

De acordo com Macedo et al (2011) os materiais compósitos são materiais resultantes da combinação de dois ou mais materiais, de composição e forma diferentes com o objetivo de produzir um único dispositivo com propriedades superiores às dos componentes unitários. Com os materiais compósitos é possível obter produtos com diferentes propriedades, entre as quais se podem citar: leveza, ductilidade, materiais resistentes a altas temperaturas, materiais duros ou resistentes ao choque.

De acordo com Missagia (2013) o emprego de materiais que contém fibras naturais, como o pó de serragem, tem grande destaque na utilização como reforço de materiais compósitos por apresentarem as fibras boas relações entre resistência mecânica e peso.

Segundo Carvalho (2000) o pó de serragem pode ser usado tanto na indústria de compósitos, aproveitado como carga, quanto em outras indústrias como na mistura com matrizes cimentícias na fabricação de argamassas e concreto para a construção civil, em matrizes cerâmicas na fabricação de telhas, como núcleo de blocos de concreto, em matrizes asfálticas para pavimentação de ruas e estradas e como massa de enchimento em diversos produtos. aterros são desviados, O gesso em pó também foi empregado como material de reforço, pois é um material de características cimentantes, pode ser utilizado como material de colagem e é um material bastante resistente. Conforme descrito por Haselein et al (2002) a propriedade que é mais distinta no gesso na utilização como colante é sua possibilidade de ganhar e perder água rapidamente. Com o aquecimento, o gesso perde água, e com o umedecimento, fica com grande plasticidade e moldabilidade. Além disso, materiais obtidos através de misturas de gesso e resíduos de madeiras possuem boas propriedades de resistência, consistência uniforme e boa trabalhabilidade.

Portanto, este estudo visa à construção de um material compósito resistente elaborado através de materiais já descartados, como o papel e o pó de serragem, e também o pó de gesso.

\section{Materiais e Métodos}

\section{Área de execução do projeto}

A fabricação e as análises dos materiais compósitos obtidos foram realizadas no Laboratório de Materiais Compósito (LMC) localizado na Universidade Federal do Tocantins campus Palmas e no Laboratório de Materiais e Estruturas (LME) localizado no Centro Universitário Luterano de Palmas (CEULP/ULBRA).

\section{Caracterização dos materiais utilizados}

O tipo de papel utilizado foi de pósconsumo formato A4 (papel de escritório) recolhido dentro da própria universidade, o pó de gesso utilizado é encontrado comercialmente em qualquer gessaria do estado e os resíduos de madeira foram fornecidos pela Marcenaria do Milton localizada em Taquaruçu no município de Palmas-TO. Os papéis foram recortados no formato de tiras em dimensões de $150 \mathrm{~mm}$ de comprimento e $30 \mathrm{~mm}$ de largura. Com o papel recortado $(40 \mathrm{~g})$ e com diferentes 
Citação: Ribeiro J. S., Serra J. C. V., Compósitos obtidos de resíduos de papel, reforçados com pó de serragem e gesso. E\&S -Engineering and Science, (2014), 2:1.

porcentagens de água $(300,500$ e 700 $\mathrm{ml}$ ), foram preparadas polpas de papéis em uma batedeira tradicional.

\section{Fabricação dos corpos de prova}

Os moldes de madeira tinham forma prismática com $40 \mathrm{~mm}$ de altura, $40 \mathrm{~mm}$ de largura e $160 \mathrm{~mm}$ de comprimento conforme recomendado pela NBR 13279:2005.

\section{Preparação dos blocos compósitos}

Após o fabrico da polpa de papel os blocos foram preparados misturando os outros materiais à polpa. Depois de retirar o excesso de água da polpa, o pó de serragem e de gesso, foram misturados a ela em diferentes proporções adotadas, além desses foi utilizado também uma pequena porcentagem de cola branca simples que neste estudo servirá apenas como aglutinante.

A porcentagem de materiais utilizados em cada modelo pode ser vista na Tabela 1 abaixo:

Tabela 1. Métodos de mistura

\begin{tabular}{llllll}
\hline Modelos & $\begin{array}{l}\text { Polpa } \\
\text { de } \\
\text { papel }\end{array}$ & $\begin{array}{l}\text { Pó } \\
\text { serragem }\end{array}$ & $\begin{array}{l}\text { Pó } \\
\text { de } \\
\text { gesso }\end{array}$ & $\begin{array}{l}\text { Cola } \\
\text { branca }\end{array}$ \\
\hline M1P351 & $35 \%$ & $15 \%$ & $45 \%$ & $5 \%$ \\
M1P352 & $35 \%$ & $45 \%$ & $15 \%$ & $5 \%$ \\
M2P501 & $50 \%$ & $20 \%$ & $25 \%$ & $5 \%$ \\
M2P502 & $50 \%$ & $15 \%$ & $35 \%$ & $5 \%$ \\
M3P751 & $75 \%$ & 0 & $20 \%$ & $5 \%$ \\
M3P752 & $75 \%$ & $20 \%$ & $0 \%$ & $5 \%$ \\
M1P351 & $35 \%$ & $15 \%$ & $45 \%$ & $5 \%$ \\
\hline
\end{tabular}

O processo de mistura foi realizado misturando todos os materiais em batedeira tradicional até a obtenção de uma pasta homogênea e em seguida a pasta foi colocada na fôrma de madeira e prensada para retirar o excesso de água, como pode ser visto na Figura 1 abaixo:
Figura 1. Pasta antes e após prensagem manual

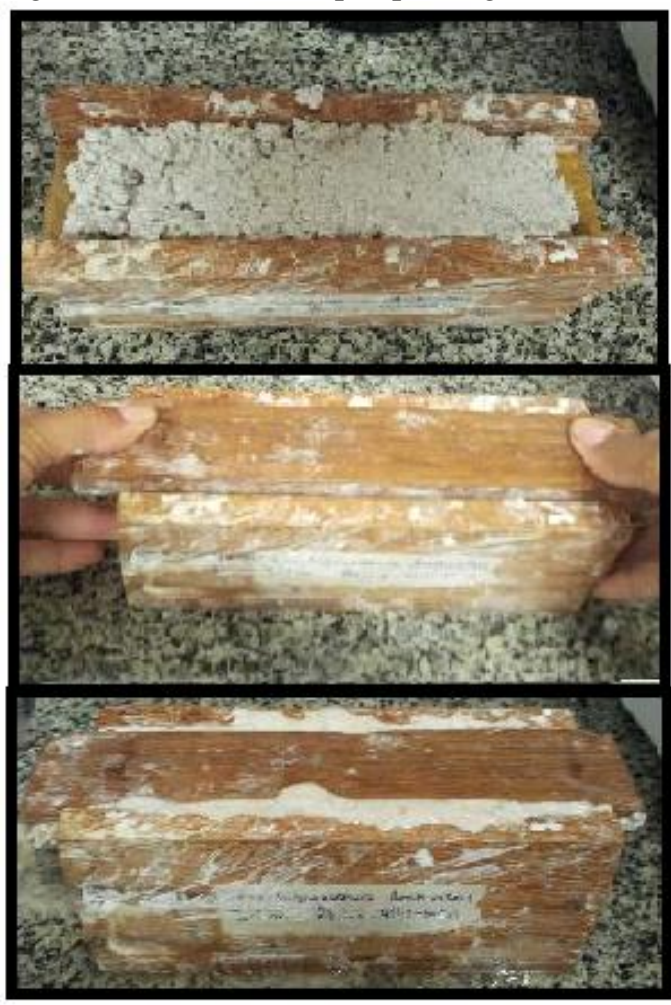

Cerca de $1 \mathrm{~h}$ após, tempo suficiente para que adquirisse resistência, os corpos de prova foram retirados dos moldes a fim de serem manuseados e acondicionados em temperatura ambiente durante 28 dias de cura, conforme recomendado pela NBR 13279:2005.

Figura 2. Compósito após ser desenformado

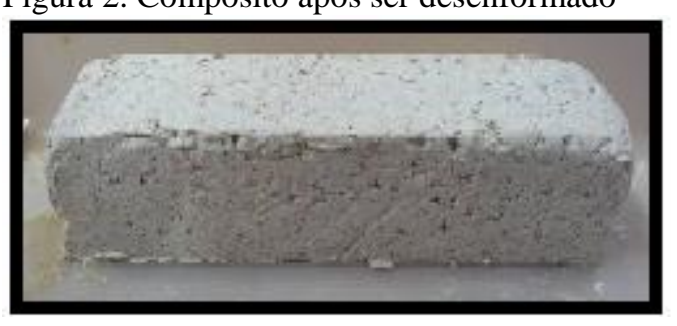

\section{Caracterização físico-mecânica}

Após secagem dos blocos procedeu-se à caracterização dos compósitos, recorrendo a testes em laboratório, de modo a avaliar o comportamento físico e mecânico das referidas composições. Deste modo, foi possível confirmar a possibilidade da sua aplicação e testar sua eficiência.

Os testes, normas e equipamentos específicos que foram utilizados nos corpos de prova estão descritos na Tabela 2 a seguir: 
Citação: Ribeiro J. S., Serra J. C. V., Compósitos obtidos de resíduos de papel, reforçados com pó de serragem e gesso. E\&S -Engineering and Science, (2014), 2:1.

Tabela 2. Testes e normas que foram realizados nos corpos de provas.

\begin{tabular}{|c|c|}
\hline Testes & Normas \\
\hline $\begin{array}{l}\text { Densidade de massa } \\
\text { aparente no estado } \\
\text { endurecido }\end{array}$ & NBR 13280:1995 \\
\hline $\begin{array}{l}\text { Absorção de água } \\
\text { por capilaridade }\end{array}$ & EN 1015-18 \\
\hline $\begin{array}{l}\text { Resistência à } \\
\text { compressão axial }\end{array}$ & NBR 13279:2005 \\
\hline $\begin{array}{l}\text { Módulo } \\
\text { elasticidade }\end{array}$ & NBR 13279:2005 \\
\hline $\begin{array}{l}\text { Resistência à tração } \\
\text { na flexão }\end{array}$ & NBR 13279:2005 \\
\hline
\end{tabular}

\section{Resultados e discussões}

Densidade de massa aparente no estado endurecido

A Densidade de massa aparente dos compósitos variou de 184,6 a 588,9 $\mathrm{kg} / \mathrm{m} 3$ e o modelo de maior densidade apresentada foi o modelo M1P351, como pode ser vista na Figura 3 a seguir:

Figura 3. Densidade de massa aparente no estado endurecido

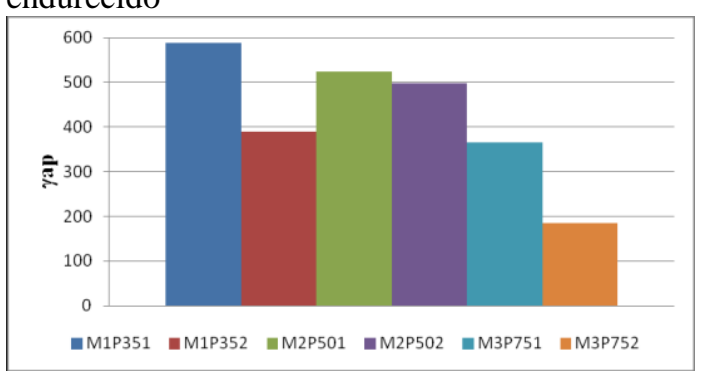

A densidade de um material pode ser modificada quando se aumenta sua massa (diminui o volume de vazios) ou diminui seu volume. A compressão ou o empacotamento dos materiais na prensagem dos compósitos é bastante influenciador nesse ensaio. Se fosse possível prensar esses compósitos de maneira mecanizado poderia ser que os compósitos tivessem densidade maiores do que os valores obtidos.

Todos os modelos foram considerados de baixa densidade e alguns dos seus valores apresentaram valores adequados quando comparados à densidade aparente no estado endurecido do gesso que para construção civil que deve estar entre 500 a $700 \mathrm{~kg} / \mathrm{m} 3$ conforme NBR 12127:1991 e a densidade aparente da argamassa que varia de 1200 a 1800 conforme NBR 13280:2005. Outros valores possuíram densidade bastante baixa quando comparados a esses materiais de construção, no entanto apesar de baixa, a densidade não influencia no desempenho dos compósitos nos ensaios de resistência que são ensaios mais significativos para construção civil.

\section{Absorção de água por capilaridade}

A quantidade máxima de água existente no seu interior pode ser vista através do valor assintótico, o qual é definido pela assíntota horizontal do gráfico mostrada na Figura 4 a seguir:

Figura 4. Curvas de absorção de água por capilaridade

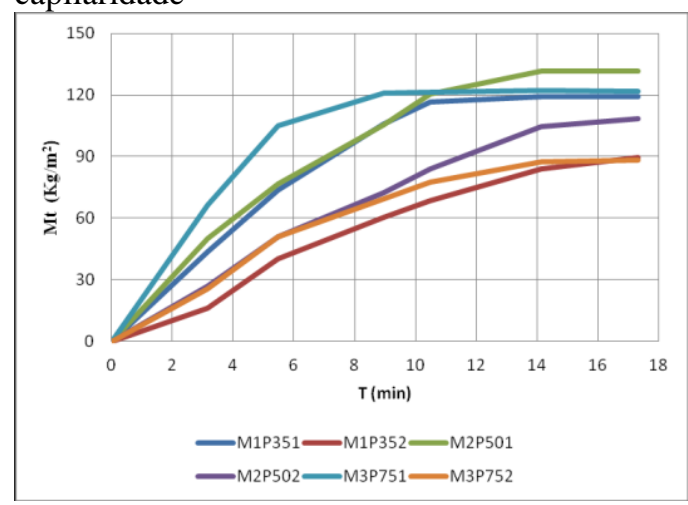

Conforme Ribeiro (2006) a absorção de água é uma característica importante no processo de moldagem de placas, pois pode interferir no enfraquecimento e na perfeição da superfície do material.

Conforme Savi (2012) a capacidade de absorção de água pode ser influenciada pelo aumento da temperatura durante a hidratação, que pode produzir um material mais poroso e, portanto, com maior capacidade de absorção de água.

Da análise efetuada à Figura 4 verificase que a absorção capilar é muito rápida inicialmente e em seguida há um ritmo notavelmente mais lento até à fase de estabilização. Esta explicação reside no fato da água penetrar primeiro nos poros de maior dimensão e em seguida nos poros de menor dimensão e nos poros cujo acesso depende destes menores (RATO, 2006). 
A estabilização dos valores das curvas de absorção capilar é o que permite calcular o valor assintótico, ou seja, quando a velocidade de absorção de água pelos provetes começa a ser muito reduzida e eles estão prestes a atingir a saturação.

O gráfico que exprime a relação entre os valores assintóticos e os coeficientes de capilaridade obtidos no ensaio pode ser visto na Figura 5 abaixo:

Figura 5. Valor assintótico e coeficiente de capilaridade.

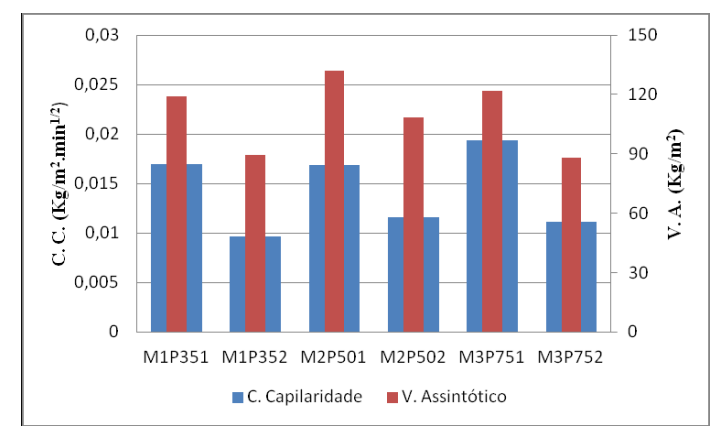

Neste ensaio é possível verificar a velocidade de absorção e a quantidade de água absorvida em determinado intervalo de tempo para cada um dos compósitos

Conforme Vicente (2012) com o intuito de diminuir os fenômenos de degradação dos materiais pretende-se que os corpos de prova tenham menores coeficientes de absorção e menores valores assintóticos, portanto pretende-se, como comportamento ideal, que os compósitos absorvam pouca quantidade de água e de forma lenta, traduzindo num valor assintótico e num coeficiente de capilaridade baixos, respectivamente.

Na Figura 5, para melhor visualização, pode ser percebido que os modelos que possuíram menores valores assintóticos e menores coeficientes de capilaridade, ou seja, absorveram menor quantidade de água e menor velocidade de absorção dentro do respectivo intervalo de tempo, foram os modelos M1P352 e M3P752, a explicação para isso pode ser de fato que esses modelos, comparando-se com os outros provetes, podem ter em seu interior poros de dimensão menores ou menor número de vazios dificultando a passagem de água. Percebe-se também que esses modelos são os que apresentam maior porcentagem de pó de serragem adicionado na sua composição, com isso conclui-se que a absorção de água diminui com a adição de fibras vegetais.

O coeficiente de capilaridade dos compósitos variaram de 0,010 a 0,019 $\mathrm{kg} / \mathrm{m}^{2} \cdot \min ^{1 / 2}$. Para construção civil esses valores atendem os valores estabelecidos pela NBR 13281:2005 que descreve que o coeficiente de capilaridade da argamassa varia de 0,015 a 0,10 $\mathrm{kg} / \mathrm{m}^{2} \cdot \min ^{1 / 2}$.

\section{Resistência à tração na flexão}

Os valores de resistência a tração na flexão variaram de 0,05 a 1,4 MPa e o modelo que apresentou melhor valor que resistência foi o modelo M1P351, como visto a seguir.

Figura 6. Resistência à tração na flexão

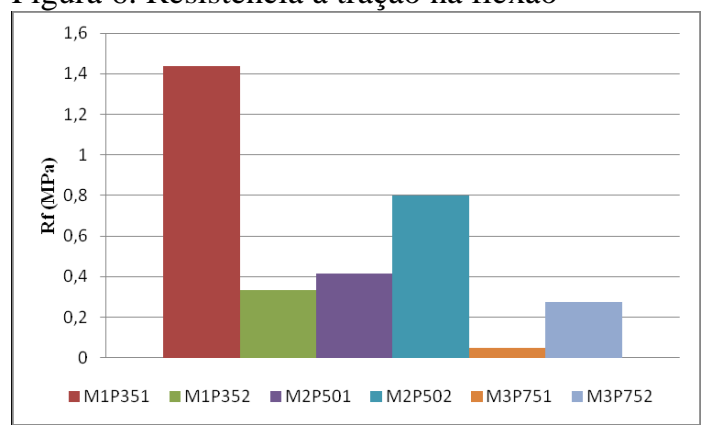

Os valores foram considerados bons quando comparados a resistência a tração na flexão do gesso que varia de 0,7 a 3,5 $\mathrm{MPa}$ e a resistência a tração a flexão da argamassa que varia de 1,5 a 3,5 segundo NBR 13281:2005.

Observou-se que a adição de fibras vegetais como o pó de serragem forneceu um aumento significativo da resistência nos compósitos, isso pode ser confirmado, pois o modelo que apresentou menor resistência à tração na flexão (M3P751) foi o modelo que não havia nenhuma porcentagem de pó de serragem em sua composição. 
Na Figura 7 abaixo pode ser visualizado a força que foi em aplicada em cada compósito até sua ruptura.

Figura 7. Força aplicada até ruptura no ensaio de tração na flexão

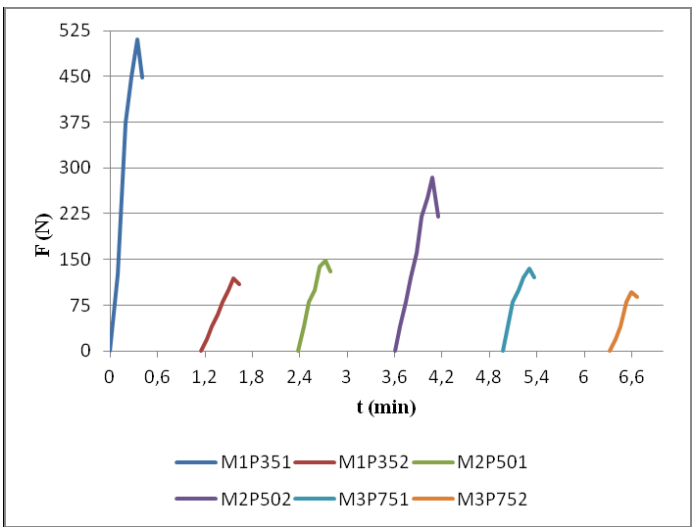

A figura acima relaciona quanto tempo o compósito levou para ruptura e quanto de força ele suportou durante esse período.

Pode-se perceber que o modelo M1P351 foi o que mais suportou uma carga bastante elevada em comparação aos outros modelos.

\section{Módulo de elasticidade}

Pode ser observado que o modelo M1P351 apresentou maior módulo de elasticidade, como visto abaixo.

Figura 8. Módulo de elasticidade (MPa)

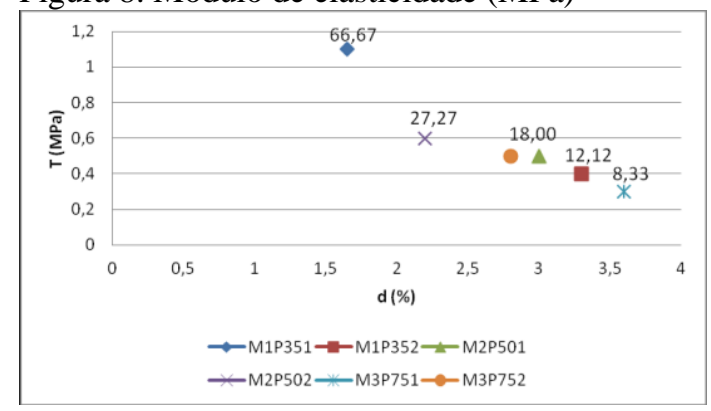

Para estruturas de alvenaria, conforme Prudêncio et al (2003) quanto maior o módulo de elasticidade das unidades, menor é $\mathrm{o}$ fator de eficiência da alvenaria. Isso ocorre porque o módulo de elasticidade da junta de argamassa e geralmente baixo. Assim, unidades muito rígidas fazem com que a variação entre a deformação da unidade e da junta seja maior, aumento assim as tensões na interface bloco/junta aumente.
De acordo com Siqueira (2006) a escolha das fibras utilizadas influencia bastante no módulo de elasticidade dos compósitos. As fibras de elevado módulo de elasticidade resultam em compósitos com elevada resistência à tração, rigidez e absorção de cargas dinâmicas. Já as fibras de baixo módulo de elasticidade e alongamento maior absorver grandes energias, tendo seus compósitos elevada resistência ao impacto e tenacidade, embora não haja grande contribuição à sua resistência.

Savi (2012) descreve em seu trabalho que ter suficiente resiliência, ou seja, seu módulo de elasticidade não deve ser alto, para que acomode as deformações da parede sem fissurar.

Aliado a isso, Prudêncio et al (2003) destacam que um incremento da resistência a compressão normalmente não implica em um aumento significativo da resistência da alvenaria. Isso ocorre porque o módulo de elasticidade não aumenta na mesma proporção que a sua resistência a compressão, fazendo com que o estado de tensões da unidade, que geralmente causa o colapso da alvenaria sob compressão, mantenha-se quase inalterado.

Os modelos apresentados poderiam ter melhor módulo de elasticidade se fosse possível saber e escolher o tipo de serragem (espécie de madeira) trabalhado, pois segundo Missagia (2013) o tipo de serragem é significativo nas propriedades mecânicas dos compósitos. Em seu trabalho a espécie de Eucalipto, cujo módulo de elasticidade é inferior ao da madeira de Ipê, apresentou os maiores valores das propriedades mecânicas.

Resistência à compressão axial

Conforme Savi (2012) a resistência à compressão de materiais agregados com gesso varia e apresenta redução com o aumento da quantidade de água de amassamento.

Os valores de resistência a compressão dos compósitos variaram de 2,5 a 8,5 $\mathrm{MPa}$, como visto abaixo. 
Figura 9. Resistência à compressão

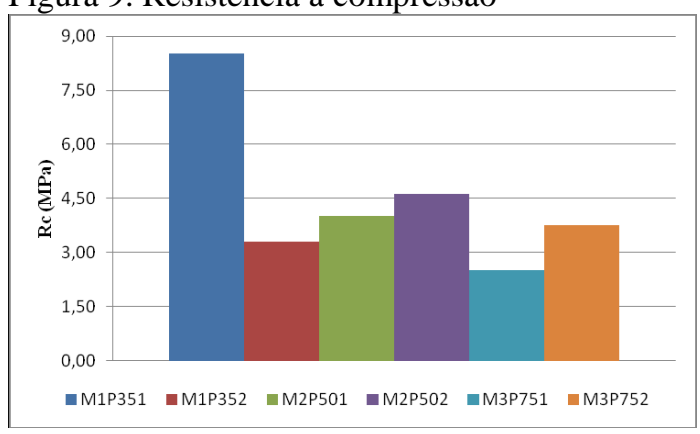

Os valores foram consideradamente bons quando comparado a resistência à compressão do gesso que deve ser maior que $8 \mathrm{MPa}$ conforme NBR 13207:1994 e a resistência a compressão da argamassa que varia de 2 a $8 \mathrm{MPa}$ conforme norma NBR 13281:2005.

De acordo com Vicente (2012) a resistência à compressão de um compósito pode aumentar à medida que se aumenta o tempo de cura, este fato pode ser ocorrido devido à umidade elevada no ambiente envolvente dos mesmos, dificultando a cura destes. Sabe-se ainda que o tempo de cura e de endurecimento de materiais compósitos com serragem é lento, quando estão em ambientes de elevada umidade.

O trabalho de Aigbomian e Fan (2013) apresentou resultados de resistência à compressão de 0,80 MPa para os seus compostos considerando-os adequados para painéis de parede e outras aplicações não estruturais com boa propriedade de isolamento térmico, possibilitando concluir, que o material aqui desenvolvido, apresenta-se adequado além destas aplicações, como reforço estrutural moderado.

\section{Conclusão}

O processo de fabricação dos compósitos desenvolvidos mostrou-se simples e possível de ser realizado em qualquer laboratório e também em grande escala.

A mistura do papel aos materiais propostos (pó de serragem e de gesso) mostrou resultados positivos a partir na análise dos ensaios mostrando que essa composição é tecnicamente viável.
No ensaio de densidade de massa no estado endurecido foi visto que todos os modelos apresentaram baixa densidade que significa que são materiais consideravelmente leves e que atenderam os valores quando se comparado a materiais de alvenaria.

Pode ser percebido no ensaio de absorção de água que a retenção de água, propriedade importante em materiais de revestimento, foi aumentada pela presença das fibras.

No ensaio de resistência a tração na flexão os modelos atenderam os valores estabelecidos quando comparados ao gesso puro e a argamassa. $\mathrm{Na}$ comparação de dois modelos, um que não possuía fibras vegetais em sua composição (M3P751) e outro que não possuía gesso em sua composição (M3P752) foi percebido que o modelo M3P752 teve uma resistência bem maior que o modelo M3P751, com isso conclui-se que a adição de fibras vegetais aumenta consideravelmente a resistência à tração na flexão de materiais compósitos.

No módulo de elasticidade pode ser notado, segundo Missagia (2013), para que os valores do módulo de elasticidade poderiam ser melhorados caracterizados se fosse possível conhecer a espécie da madeira do pó de serragem utilizado na composição dos compósitos, pois o tipo de madeira influencia bastante no módulo de elasticidade de materiais.

No ensaio de compressão axial os valores foram considerados bons se os compósitos forem utilizados para fins de alvenaria interna. De acordo com as normas para construção civil, se fosse aumentado o tempo de cura dos compósitos seria possível aumentar a resistência dos mesmos.

Os resultados dos ensaios permitiu concluir que os compósitos atingiram os objetivos propostos e tiveram bom desempenho quando se comparado a outros materiais para construção como o gesso puro e a argamassa.

Os compósitos desenvolvidos têm a particularidade de serem sustentáveis, 
devido aos seus componentes reciclados (papel e pó de serragem) e vale ressaltar que o composto aqui desenvolvido não apresentou custo alto, sendo que o benefício incorporado será, além das questões ambientais, uma possibilidade tanto de aproveitamento do resíduo, como possibilidade de geração de empregos na fabricação deste material.

$\mathrm{O}$ modelo que apresentou melhor desempenho para ser aplicado na construção civil, quando o comparando a outros materiais de construção,foi o modelo M1P351.

\section{Referências}

ASSOCIAÇÃO BRASILEIRA DE NORMAS TÉCNICAS. NBR 13280: Argamassa para assentamento de paredes e revestimento de paredes e tetos - Determinação da densidade de massa e do teor de ar incorporado, 1995.

MB 3470: Gesso para construção Determinação das propriedades mecânicas, 1991.

_. NBR 12129: Gesso para construção - Determinação das propriedades físicas do pó, 1997.

_. NBR 13207: Gesso para construção civil, 1994.

NBR 13279: Argamassa para assentamento e revestimento de paredes e tetos - Determinação da resistência à tração na flexão e à compressão, 2005.

NBR 13281: Argamassa para assentamento e revestimento de paredes e tetos - Requisitos, 2005.

CALEGARI, L. et al. Adição de aparas de papel reciclável na fabricação de chapas de madeira aglomerada. Ciência Florestal, Santa Maria, v. 14, n. 1, p. 193-204, 2004.
CARDOSO, M.T. et al. Propriedades físicas e mecânicas de papéis reciclados utilizados para fabricação de tubetes. Ciência Florestal, Santa Maria, v. 22, n. 2, p 403-411, abr/jun 2012.

CARVALHO, A. F. Disposição de resíduos sólidos na indústria de compósitos. Anais do III Seminário de Desenvolvimento Sustentável e a Reciclagem na Construção Civil: Práticas Recomendadas, 2000.

EN 1015-18. Methods of test for mortar for masonry - Part 18: Determination of water absorption coefficient due to capillary action of hardened mortar. [Brussels]: European Committee for Standardization (CEN), 2002.

HASELEIN, C.R. et al. Fabricação de chapas de partículas aglomeradas usando gesso como material cimentante. Ciência Florestal, Santa Maria, v. 12, n. 1, p. 81-88, 2002.

MACEDO, M. C. et al. Materiais compósitos à base de gesso e isopor para construção de casas populares. Revista HOLOS, ano 27, vol 5, ISSN 1807-1600, 2011.

MISSAGIA, Z. M. V. Compósitos particulados em matriz epóxi reforçados com serragem, cimento e silicato de magnésio. Programa de Pósgraduação em Engenharia Mecânica (PPMEC), São João Del-Rei - UFSJ, 2013.

RATO, N. Influência da microestrutura morfológica no comportamento de argamassas. Tese de Doutoramento em Engenharia Civil. Lisboa. Caparica, FCT/UNL, 2006. 
SAVI, O. Produção de placas de forro com a reciclagem do gesso. Universidade Estadual de Maringá (UEM)- Programa de pós-graduação em engenharia urbana, Maringá, 2012.

SENA, $C$ et al. Máquina de préreciclagem de papel. E-xacta, Belo Horizonte, v. 4, n. 2, Edição Especial Interdisciplinaridade. p. 65-74. (2011). Editora UniBH.

SIQUEIRA, J. E. B. Utilização de fibras naturais e sintéticas em argamassas de revestimento de alvenaria: estudo comparativo de desempenho. Universidade federal de Santa Catarina (UFSC) - Programa de pós-graduação em engenharia civil, Florianópolis, 2006.

VICENTE, A. M. M. Caracterização de revestimentos sujeitos à acção da água e sais. Estudo Físico e Mecânico da Influência dos Agregados. Lisboa: ISEL, 2012. 